\title{
Heat shock transcription factor 1 affects kidney tubular cell migration by regulating the TGF-ß1-Smad2/3 signaling pathway
}

\author{
QIANG LOU ${ }^{1 *}$, YUANYUAN LI $^{1 *}$, BEIBEI HOU ${ }^{2}$, YONGLIAN LIU $^{1}$, \\ YAN ZHANG $^{1}$, JIELU HAO ${ }^{3}$ and YUANFANG MA ${ }^{1}$ \\ ${ }^{1}$ Joint National Laboratory for Antibody Drug Engineering and ${ }^{2}$ International Office of Henan University, \\ Henan University, Kaifeng, Henan 475004; ${ }^{3}$ Department of Nephrology, Changzheng Hospital \\ Affiliated to Second Military Medical University, Shanghai 200003, P.R. China
}

Received January 3, 2019; Accepted August 23, 2019

DOI: $10.3892 / \mathrm{mmr} .2019 .10689$

\begin{abstract}
Cell migration is important for renal recovery from tubular cell injury. Heat shock transcription factor 1 (HSF1) is a well-studied regulatory factor that is active during acute kidney injury. HSF1 is also involved in the migration process during tumor metastasis. Therefore, we hypothesized that HSF1 may promote the recovery of renal function by affecting kidney tubular cell migration. A wound healing assay was used to examine the cell migration rate. The results demonstrated that the migration of rat kidney proximal tubular cells (RPTCs) was increased following knockdown of HSF1. In addition, the invasion ability of HSF1 knockdown RPTCs was also significantly upregulated. The present study also identified that transforming growth factor- $\beta 1$ (TGF- $\beta 1$ ) was highly expressed at the edge of the wound in control cells, and its expression was further increased upon knockdown of HSF1. Inhibition of TGF- $\beta 1$ signaling prevented RPTC HSF1 knockdown cell migration, suggesting that HSF1-regulated RPTC cell migration was dependent on the TGF- $\beta 1$ signaling pathway. Furthermore, phosphorylation of TGF- $\beta 1$ and Smad2/3 was induced in HSF1 knockdown cells. Together, these results suggest that HSF1 may suppress RPTC migration
\end{abstract}

Correspondence to: Professor Yuanfang Ma or Dr Qiang Lou, Joint National Laboratory for Antibody Drug Engineering, Henan University, 1 North Jinming Avenue, Kaifeng, Henan 475004, P.R. China

E-mail: mayf@henu.edu.cn

E-mail: qiang_lou@126.com

${ }^{*}$ Contributed equally

Abbreviations: RPTC, rat kidney proximal tubular cells; HSF1, heat shock transcription factor 1 ; TGF- $\beta 1$, transforming growth factor- $\beta 1$; AKI, acute kidney injury; EMT, epithelial-mesenchymal transition; NC, negative control; KD, HSF1 knockdown

Key words: heat shock transcription factor 1; kidney tubular cell migration; transforming growth factor- $\beta 1$ pathway by inhibiting the activation of the TGF- $\beta 1-\mathrm{Smad} 2 / 3$ signaling pathway.

\section{Introduction}

The kidney has the ability to recover from ischemic or toxic injury. During acute tubular cell injury, the basement membrane of the tubules becomes rough, suggesting that normal cells migrate to the injured basement membrane. However, the migrated cells often lose their polarity and change in structure. Renal proximal tubular cells (RPTCs) are the primary cell type responsible for regeneration of tubular epithelial cells during acute kidney injury (AKI) (1). Renal tubular epithelial cell migration was decreased following treatment with dimethyloxallyl glycine, which upregulates hypoxia-inducible factor expression (2), suggesting that cell migration may be affected by hypoxia or its associated regulatory factors.

Heat shock transcription factor 1 (HSF1) is a well-studied regulatory factor that is active during AKI. In our previous study, HSF1 was markedly activated and exhibited a protective effect against cisplatin-induced AKI (3). However, during ischemic renal injury, HSF1 activation may contribute to early injury (4). The effect of HSF1 on cell migration is hypothesized to be different in different cell lines. Several studies have suggested that HSF1 promoted cell migration, particularly in cancer cells, including pancreatic cancer (5), osteosarcoma (6), hepatocellular carcinoma $(7,8)$ and melanoma cells $(9)$. However, in lung epithelium, activation of heat shock response decreased the rate of wound closure (10). The precise role of HSF1 in kidney tubular cell migration and self-repairing remains largely unknown.

In addition to HSF1, transforming growth factor- $\beta 1$ (TGF- $\beta 1$ ) also serves a role in cell migration. TGF- $\beta 1$ may be cleaved by proteolytic enzymes to form a 112-amino acid peptide, which binds to its receptors and transduce signals through conserved Smad proteins. The TGF- $\beta$-Smad signaling pathway was demonstrated to be activated during gastric cancer (11) and lung adenocarcinoma (12) cell migration and invasion, and in the process of epithelial-mesenchymal transition (EMT). TGF- $\beta$ may trigger EMT and increase the migratory and invasive capacities of nasopharyngeal carcinoma cells (13) and breast carcinoma MCF-7 and MDA-MB-231 cell lines $(14,15)$. The stimulation of TGF- $\beta 1$ enhanced podocyte adhesion and migration (16). 
In renal carcinoma 769-P and OSRC cell lines, TGF- $\beta 1$ also facilitates migration and invasion, which is primarily associated with the regulation of the extracellular signal-regulated kinase (ERK) and c-Jun N-terminal kinase (JNK) signaling pathways (17). In vascular smooth muscle cells (VSMCs), proliferation and migration were inhibited by microRNA-145-5p, which was regulated by TGF- $\beta$ signaling pathway proteins, including Smad2, Smad3 and TGF- $\beta$ (16). The same phenomenon was observed in cervical cancer cells, whose proliferation and migration were decreased by $\mathrm{C}$ glycoprotein, and this process was accompanied by decreased expression levels of TGF- $\beta 1$, matrix metalloproteinase (MMP)-2 and MMP-9 (18). However, in a chemical model of RPTC cell injury and regeneration, TGF- $\beta 1$ treatment inhibited the self-repair capability of the injured monolayers (19). TGF- $\beta$ receptor inhibitors did not affect redifferentiation of rat kidney proximal tubular cells (RPTCs) following $\mathrm{H} 2 \mathrm{O} 2$ injury (20). To date, the precise role of the TGF- $\beta$ signaling pathway and HSF1 activation in renal tubular cell repair remain unknown.

In the present study, the functional role of HSF1 and associated signaling events in RPTC cell migration were investigated. Our results demonstrated that HSF1 decreased the activation of the TGF- $\beta-\operatorname{Smad} 2 / 3$ pathway, and thereby inhibited the RPTC cell migration and invasion processes.

\section{Materials and methods}

Cell culture. RPTCs were originally obtained from Dr. Hopfer (Case Western Reserve University). RPTC HSF1 knockdown and scramble cell lines were constructed as described in our previous study (3). The HSF1 short hairpin (shRNA) plasmids were purchased from Qiagen, Inc. (cat. no. 336312 KR47022H). All shRNA plasmids were used at a concentration of $50 \mathrm{ng} / \mathrm{ml}$. The scramble and shRNA target sequences for rat HSF1 were 5'-GGAATCTCATTCGATGCATAC-3' and 5'-TGTCAACAAGCTCATCCAATT-3', respectively. Lipofectamine ${ }^{\circledR} 2000$ was purchased from Thermo Fisher Scientific, Inc. RPTCs were plated at a density of $1 \times 10^{6}$ cells per dish in $35 \mathrm{~mm}$ dishes. The cells reached $100 \%$ confluency within $24 \mathrm{~h}$. The cells were subcultured or plated for subsequent experiments $72 \mathrm{~h}$ after transfection. RPTCs were cultured in Ham's F-12-Dulbecco's modified Eagle's medium (DMEM; 12400024; Thermo Fisher Scientific, Inc.) containing transferrin $(5 \mu \mathrm{g} / \mathrm{ml})$, insulin $(5 \mu \mathrm{g} / \mathrm{ml})$, epidermal growth factor (EGF; $1 \mathrm{ng} / \mathrm{ml}$ ), dexamethasone $(4 \mu \mathrm{g} / \mathrm{ml}), 10 \%$ FBS and $1 \%$ Antibiotic-Antimycotic (15240062; Thermo Fisher Scientific, Inc.).

Western blot analysis. HSF1 knockdown and scramble cells were cultured in a $3.5 \mathrm{~cm}$ dish. The cells were treated with the TGF- $\beta 1$ inhibitor SB431542 or with DMSO at room temperature for $24 \mathrm{~h}$. Proteins were extracted with SDS lysis solution containing $1 \%$ protease inhibitor cocktail (cat. no. 78430; Thermo Fisher Scientific, Inc.) and were then quantified using a BCA assay. A total of $\sim 30 \mu \mathrm{g}$ protein was subjected to $12 \%$ SDS-PAGE and transferred to PVDF membranes. The membranes were incubated with primary antibodies at $4^{\circ} \mathrm{C}$ overnight, including rabbit polyclonal anti-HSF1 (1:1,000; cat. no. 4356S; Cell Signaling Technology, Inc.), rabbit polyclonal anti-TGF- $\beta 1$ (1:500; cat. no. ab66043; Abcam), rabbit monoclonal anti-Smad2/3 (D7G7; 1:1,000; cat. no. 8685; Cell Signaling Technology, Inc.), rabbit monoclonal anti-phospho-Smad2 (Ser465/467)/Smad3 (Ser423/425) (D27F4; 1:1,000; cat. no. 8828; Cell Signaling Technology, Inc.), mouse monoclonal anti-Ki67 (8D5; 1:500; cat. no. NBP2-22112; Novus Biologicals, LLC.) and mouse monoclonal anti-GAPDH (1:10,000; cat. no. AC002; ABclonal Biotech Co., Ltd.) antibodies. The corresponding secondary antibodies were horseradish peroxidase-conjugated goat anti-rabbit (1:5,000; cat. no. 111-035-003; Jackson ImmunoResearch Laboratories, Inc.) and goat anti-mouse (1:5,000; cat. no. 115-035-003; Jackson ImmunoResearch Laboratories, Inc.) antibodies. The signal intensities were visualized via enhanced chemiluminescence and quantified with ImageJ 1.51 software (National Institutes of Health). GAPDH was used as an internal control. The protein expression levels in the experimental or control groups were normalized to GAPDH.

Immunofluorescence. HSF1 knockdown and scramble cells were cultured in $35 \mathrm{~mm}$ dishes at $37^{\circ} \mathrm{C}$ until $100 \%$ confluent, scratched with a $1 \mathrm{ml}$ pipette tip across the maximum diameter, and cultured at $37^{\circ} \mathrm{C}$ for additional 6,12 or $24 \mathrm{~h}$. The expression and cellular localization of TGF- $\beta 1$ was determined by immunofluorescence with a polyclonal antibody against TGF- $\beta 1$, as described previously (21). Following wound healing, cells were washed with PBS, fixed in $4 \%$ paraformaldehyde (Tianjin Zhiyuan Chemical Reagent Co., Ltd.) in PBS at room temperature for $15 \mathrm{~min}$, permeabilized with $-20^{\circ} \mathrm{C}$ precooled $100 \%$ methanol for $10 \mathrm{~min}$ and then washed with PBS. Following blocking in 5\% BSA (Sigma-Aldrich; Merck KGaA) buffer at room temperature for $\sim 1 \mathrm{~h}$, the cells were incubated with rabbit polyclonal anti-TGF- $\beta 1$ antibody (1:500; cat. no. ab66043; Abcam) overnight at $4^{\circ} \mathrm{C}$ and then washed with PBS. Next, Alexa Fluor 488-conjugated goat anti-rat IgG secondary antibody (1:500; cat. no. A-11006; Thermo Fisher Scientific, Inc.) was used in PBS buffer containing $1 \%$ BSA for $1 \mathrm{~h}$ at room temperature. Coverslips were mounted with Prolong Gold Antifade Mountant with DAPI (cat. no. P36941; Thermo Fisher Scientific, Inc.) and viewed using fluorescence microscopy (magnification, x100). Images were analyzed using ImageJ 1.51 software (National Institutes of Health).

Wound healing assay. The wound healing ability of RPTCs was evaluated as described previously (22). HSF1 knockdown (KD) and scramble negative control (NC) cells were seeded in $35 \mathrm{~mm}$ dishes at a density of $1 \times 10^{6}$ cells per dish. The next day, wounds were created with a 1-ml pipette tip and were allowed to heal for 6,12 or $24 \mathrm{~h}$. Images of the cells were captured at the indicated time points $(6,12$ and $24 \mathrm{~h}$ after scratching) with an Olympus CKX41 microscope (magnification; x100; Olympus Corporation). The healing distance was measured using Leica Application Suite V4.2 microscope software (Leica Microsystems, Inc.). Data were calculated as percentages of healing distance relative to the initial wound width. To evaluate the effect of TGF- $\beta 1$ inhibitor on the migration speed of RPTC HSF1 knockdown and scramble cells, the cells were incubated in culture medium with the TGF- $\beta 1$ inhibitor SB431542 or with DMSO prior to the wound healing assay. The percentages of healing distance were calculated as described above. The percentage difference upon treatment with or without TGF- $\beta 1$ inhibitor in the NC group was 
A

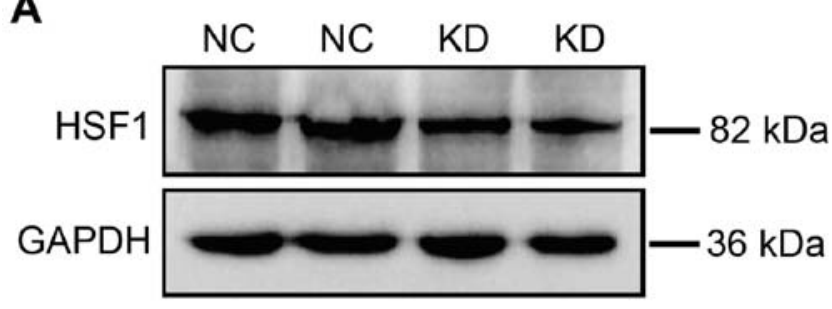

B

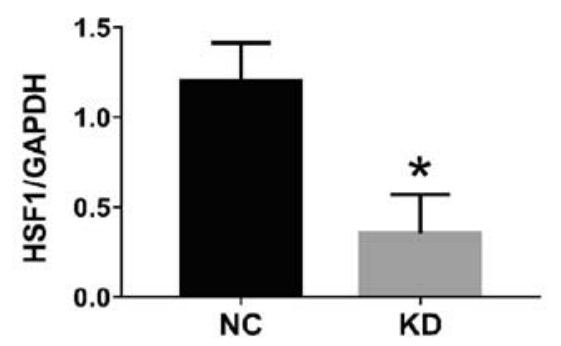

C

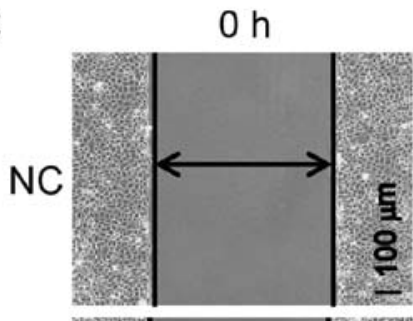

$6 \mathrm{~h}$
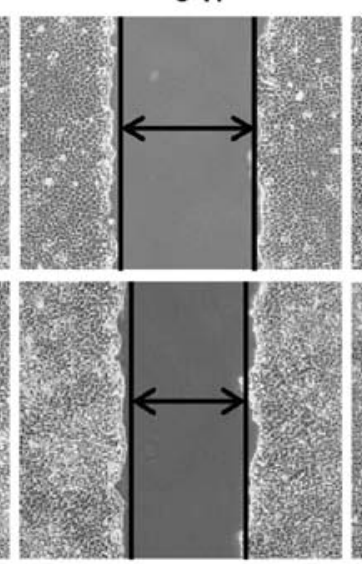

$12 \mathrm{~h}$
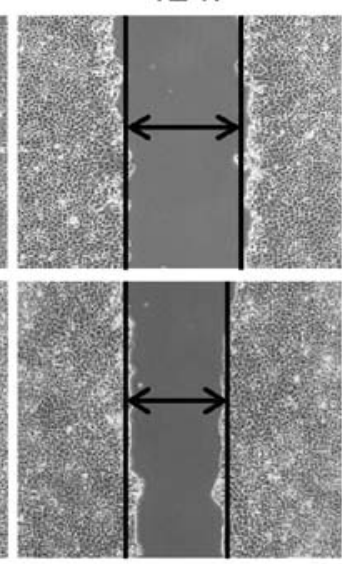

$24 \mathrm{~h}$

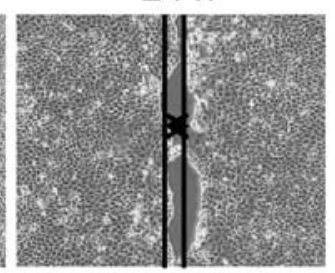

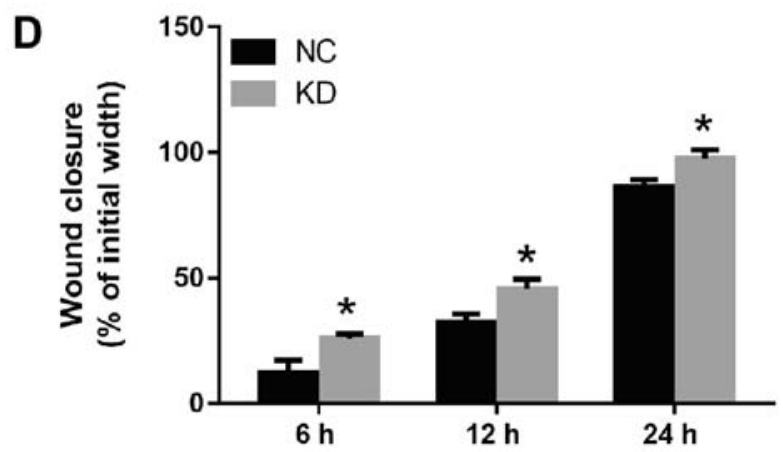

Figure 1. HSF1 KD suppresses the migratory abilities of RPTCs. (A) Western blot analysis of HSF1 expression in an RPTC cell line stably transfected with HSF1 shRNA. (B) Densitometric analysis of the relative expression of HSF1. (C) Wound healing assay of KD and NC cells at 6, 12 and $24 \mathrm{~h}$. Magnification, x100. (D) The percentages of healing distance relative to the initial wound width were summarized using a histogram. Data represent the mean \pm standard deviation of 3 independent experiments. "P<0.05 vs. NC group. HSF1, heat shock transcription factor 1; KD, knockdown; RPTC, rat kidney proximal tubular cell; NC, negative control.

compared with that in the KD group in the $0-6$ or $6-12 \mathrm{~h}$ time frame.

Transwell assay. To evaluate the effect of HSF1 on the invasion ability of RPTCs, HSF1 KD and scramble cells $\left(8 \times 10^{4}\right)$ were seeded in serum-free DMEM-F12 in the upper compartment of a Matrigel Invasion Chamber with $8 \mu \mathrm{m}$ pore size (cat. no., 08-774-121; Thermo Fisher Scientific, Inc.). The lower chamber was loaded with DMEM-F12 containing 10\% FBS. After $12 \mathrm{~h}$ incubation at $37^{\circ} \mathrm{C}$, the cells on the lower surface were fixed with $75 \%$ cold ethanol for $10 \mathrm{~min}$ and stained with $1 \%$ crystal violet for $5 \mathrm{~min}$ at room temperature. Cells in 6 randomly selected fields were observed under an Olympus CKX41 microscope (Olympus Corporation) at magnification, $\mathrm{x} 100$. The experiments were repeated 3 times.

Cell proliferation assay. RPTC HSF1 KD and scramble cells $\left(5 \times 10^{5}\right)$ were incubated in $35 \mathrm{~mm}$ dishes at $37^{\circ} \mathrm{C}$. After $0,12,24$ and $48 \mathrm{~h}$, cells were washed with PBS 3 times and then stained with $0.4 \%$ trypan blue solution (cat. no., T8154; Sigma-Aldrich; Merck KGaA). Cell proliferation was measured by counting the number of stained cells. Cells were observed under an Olympus CKX41 microscope (magnification, x200; Olympus Corporation). Relative cell proliferation was calculated from 5 fields of view. A total of $\geq 3$ independent repeat experiments were performed.

Statistical analysis. Data were expressed as the mean \pm standard error of the mean of 3 independent experiments and analyzed with GraphPad Prism v.7.00 software (GraphPad Software, Inc.). The statistical difference between two groups was analyzed by Student's t-test. The statistical differences between multiple groups were analyzed by two-way analysis of variance followed by a Bonferroni post-hoc test. $\mathrm{P}<0.05$ was considered to indicate a statistically significant difference. 
A

$\mathrm{Oh}$

$12 \mathrm{~h}$

$24 \mathrm{~h}$
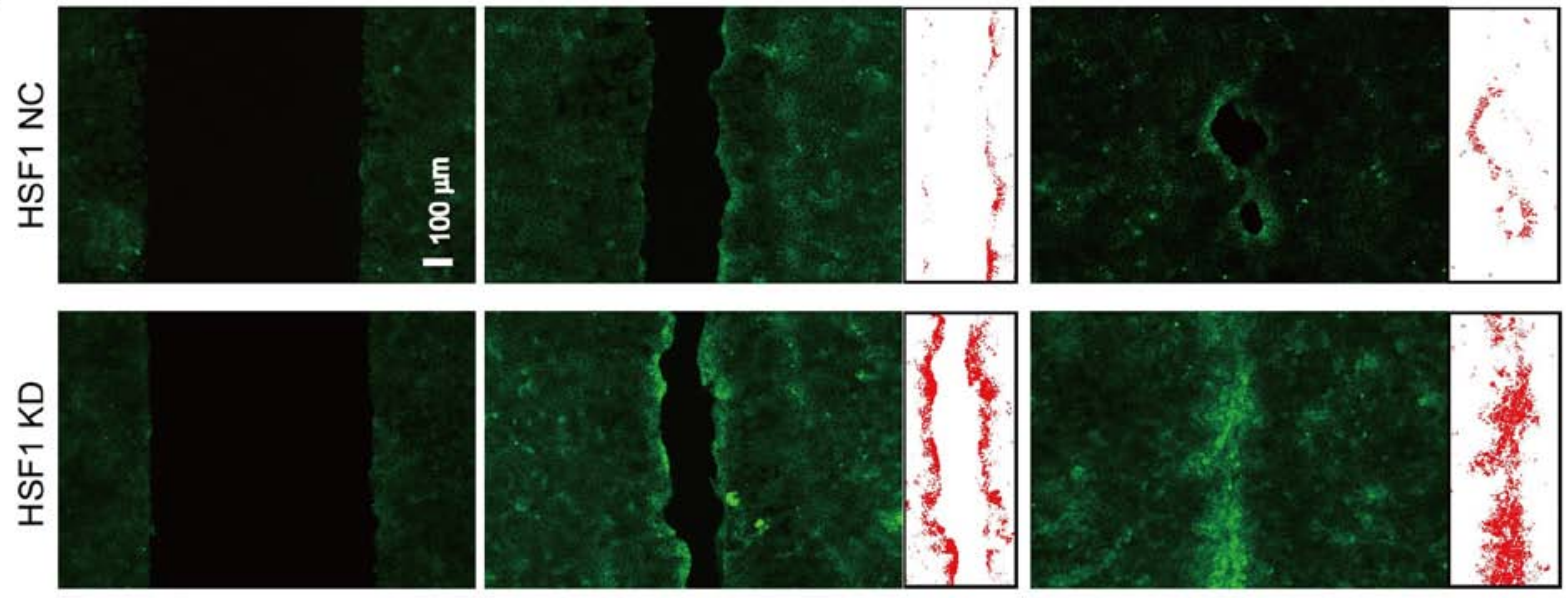

B

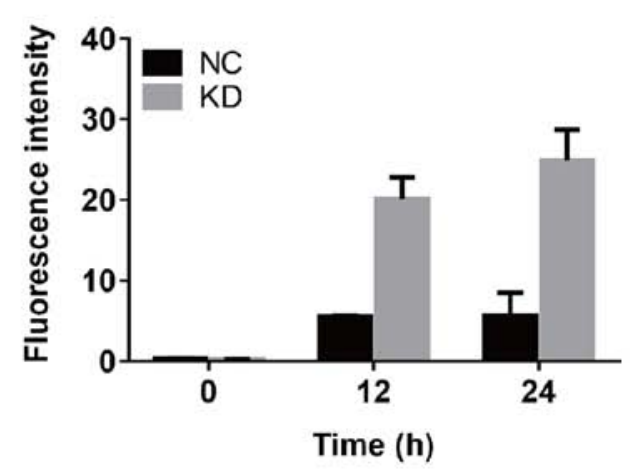

C

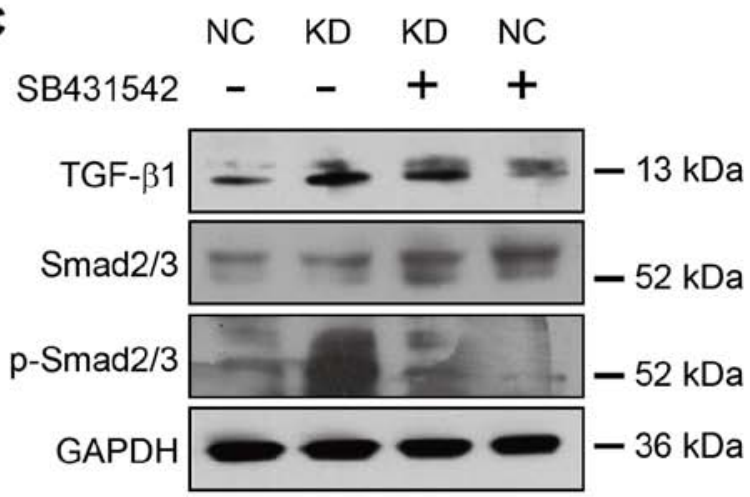

D

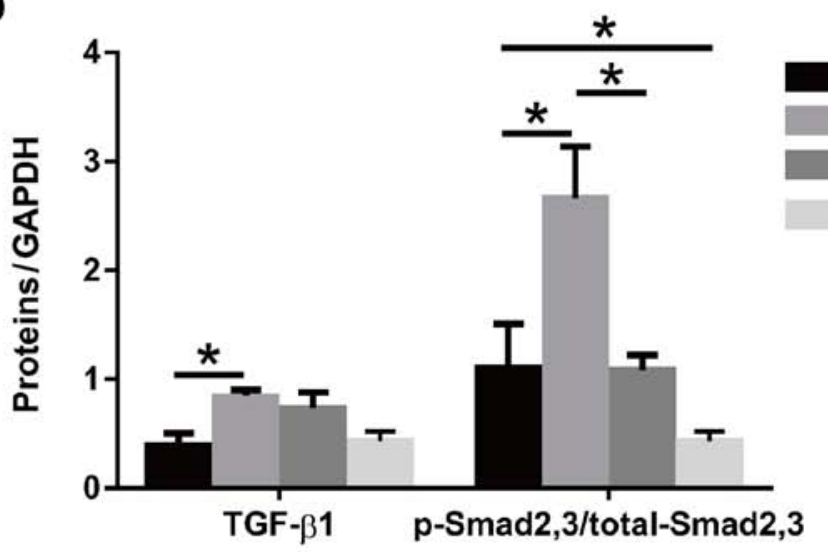

Figure 2. TGF- $\beta 1$ signaling pathway protein expression was increased during wound healing. (A) The expression and localization of TGF- $\beta 1$ during wound healing were determined by immunofluorescence staining. The wound margin was analyzed using ImageJ 1.51 software. Magnification, x100. Scale bar, $100 \mu \mathrm{m}$ (B) Histogram summarizing the fluorescence intensity of TGF- $\beta 1$ after 0,12 and $24 \mathrm{~h}$ of wound healing. (C) Upon treatment of HSF1 NC and KD cells with or without SB431542, the expression levels of TGF- $\beta 1$ and p-Smad2/Smad3 were examined by western blot analysis. (D) The gray-scale value of TGF- $\beta 1$ and $\mathrm{p}$-Smad2/Smad3 proteins were quantified and summarized in a histogram. ${ }^{*} \mathrm{P}<0.05$. TGF- $\beta 1$, transforming growth factor- $\beta 1$; HSF1, heat shock transcription factor 1; KD, knockdown; NC, negative control; p, phosphorylated.

\section{Results}

HSF1 knockdown promotes RPTCs migration. To determine the effect of HSF1 on the rate of RPTC cell migration, HSF1 KD and scramble NC cell lines were constructed by stably transfecting HSF1 shRNA or scramble sequence in RPTCs. The HSF1 expression level in KD cells was decreased by $\sim 70.5 \%$ compared with NC transfected cells (Fig. 1A and B). HSF1 KD and NC cells were scratched with a $1 \mathrm{ml}$ pipette tip and then cultured for 6,12 or $24 \mathrm{~h}$. The HSF1 KD cells exhibited an increased migration rate compared with the HSF1 NC cells. The wound closure rates in the KD and NC cells were 25.9 and $12.1 \%$ at $6 \mathrm{~h}, 45.7$ and $32.3 \%$ at $12 \mathrm{~h}$, and 97.4 and $86.6 \%$ at $24 \mathrm{~h}$, respectively (Fig. 1C and D).

HSF1 inhibits TGF- $\beta$ signaling during wound healing. The fluorescence intensity of TGF- $\beta 1$ immediately following wounding was weak, and after 12 and $24 \mathrm{~h}$, the fluorescence intensity became more marked. Notably, TGF- $\beta 1$ expression 
A

A

$\mathrm{Oh}$

$6 \mathrm{~h}$
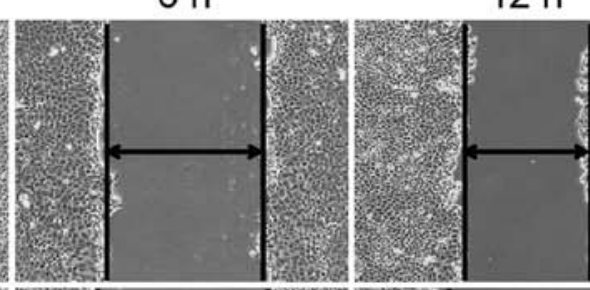

$12 \mathrm{~h}$

$24 \mathrm{~h}$
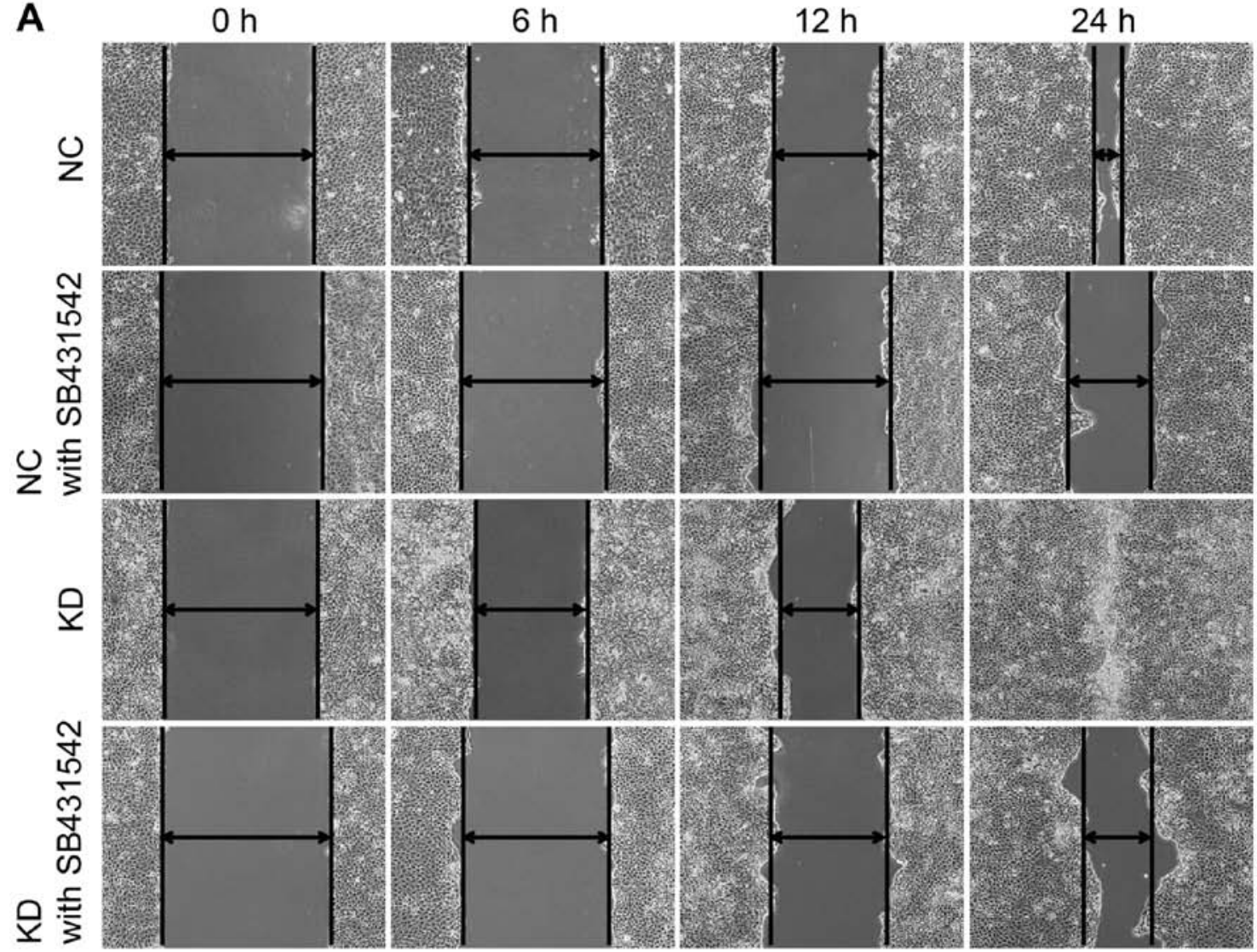

B
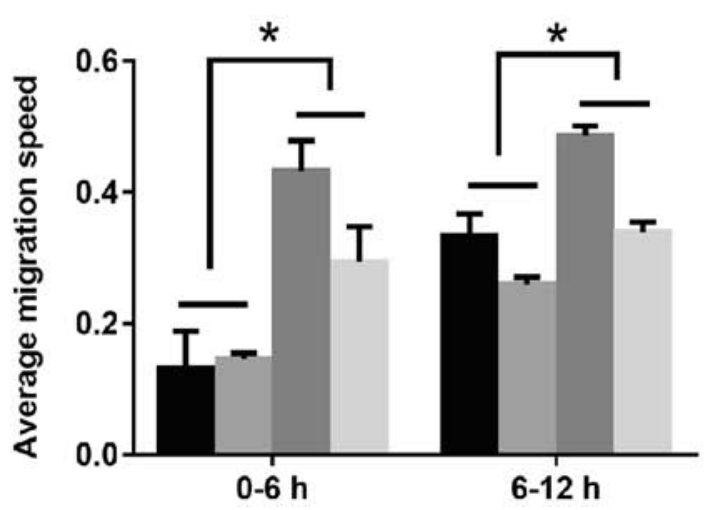

NC

NC with TGF- $\beta$ inhibitor

KD

KD with TGF- $\beta$ inhibitor

Figure 3. TGF- $\beta 1$ inhibitor SB431542 attenuates the wound healing ability of RPTCs. (A) RPTCs were scratch-wounded and then incubated with or without the TGF- $\beta 1$ inhibitor SB431542, and wound healing distance was observed with a microscope. Magnification, x100. (B) The percentage difference of healing distance relative to the initial wound width following treatment with or without TGF- $\beta 1$ inhibitor in the NC group was compared with that in the KD group at the $0-6$ or $6-12 \mathrm{~h}$ time frame. Data represent the mean \pm standard deviation of 3 independent experiments. "P<0.05 vs. NC cells. RPTC, rat kidney proximal tubular cell; TGF- $\beta 1$, transforming growth factor- $\beta 1$; NC, negative control; KD, knockdown.

was predominantly distributed in cells at the edge of the wound (Fig. 2A). Compared with HSF1 NC cells, HSF1 KD cells exhibited more marked fluorescence intensity at each time point during wound healing, indicating that TGF- $\beta 1$ expression was significantly increased compared with the corresponding control (Fig. 2B). The increased expression level of TGF- $\beta 1$ upon HSF1 knockdown was additionally confirmed by western blot analysis (Fig. 2C and D). In addition, the phosphorylation of $\mathrm{Smad} 2 / 3$, which is downstream of the TGF- $\beta$ signaling pathway, was also upregulated in HSF1 KD cells. Notably, the TGF- $\beta 1$ inhibitor SB431542 exerted a significantly suppressive effect on $\mathrm{Smad} 2 / 3$ phosphorylation (Fig. 2C and D), and was used in subsequent experiments.
TGF inhibitor suppresses RPTC wound healing ability. To additionally verify the effect of HSF1 on TGF- $\beta 1$ activation during wound healing, the TGF- $\beta 1$ inhibitor SB431542 was applied prior to the wounding process. The percentage difference of migration in the NC group was compared with that in the KD group in the 0-6 and 6-12 h time frames. As indicated in Fig. 3A, SB431542 treatment markedly decreased the rate of wound healing. Compared with the HSF1 NC cells, SB431542 treatment significantly augmented the decrease in migration rate in KD cells, particularly between 0 and $6 \mathrm{~h}$ (Fig. 3B). Upon treatment with SB431542, the migration rate decreased by $32.2 \%$ in KD cells and by $9.47 \%$ in NC cells at $0-6 \mathrm{~h}$, and by $30.3 \%$ in KD cells and $22.1 \%$ in NC cells at 6-12 h. 
A

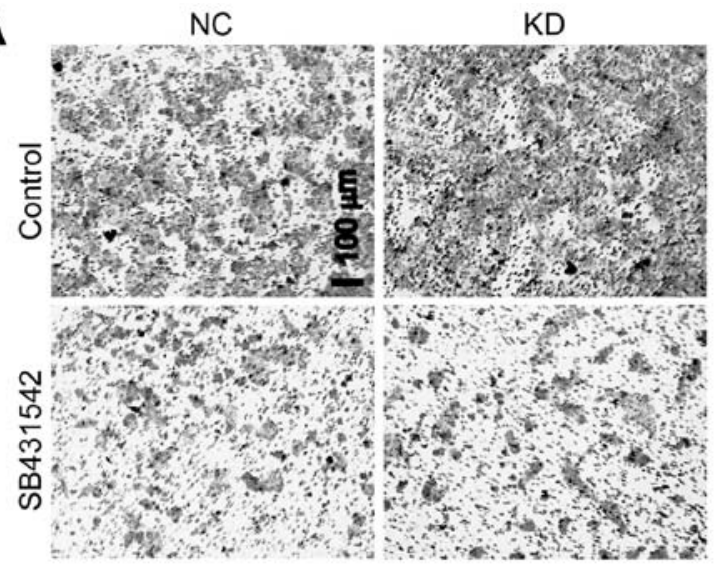

B
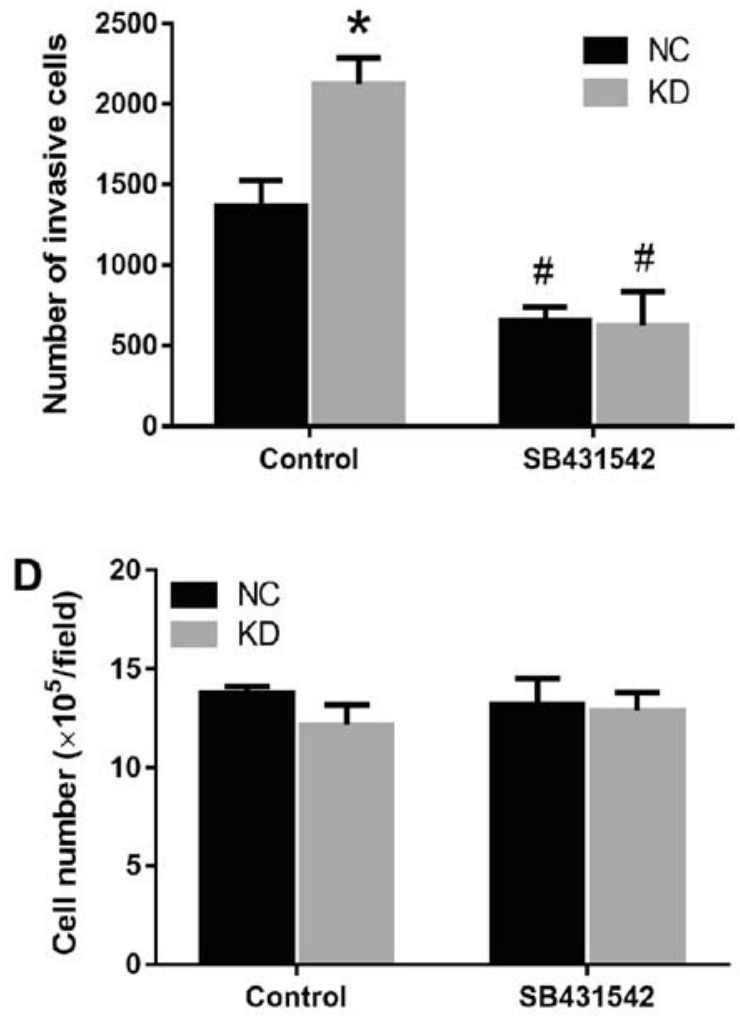

Figure 4. TGF- $\beta 1$ inhibitor SB431542 prevents the enhancing effect of HSF1 silencing on the invasive ability of RPTCs. (A) Transwell assay was performed to determine the cell invasive abilities of HSF1 KD and negative control cells treated with or without the TGF- $\beta 1$ inhibitor SB431542. Magnification, x100. Scale bar, $100 \mu \mathrm{m}$. (B) The number of invasive cells was quantified and plotted as a histogram. Data represent the mean \pm standard deviation of 3 independent experiments. "P<0.05 vs. NC; ${ }^{~ P}<0.05$ vs. respective control groups. (C) RPTC HSF1 KD and scramble cells were cultured for $0,12,24$ and 48 h. Cells were washed with PBS 3 times and then stained with trypan blue. Cell proliferation was measured by counting the cell numbers. (D) RPTC HSF1 KD and scramble cells were cultured with or without the TGF- $\beta 1$ inhibitor SB431542 for $24 \mathrm{~h}$. Cell proliferation was measured by counting the cell number. TGF- $\beta 1$, transforming growth factor- $\beta 1$; HSF1, heat shock transcription factor 1; RPTC, rat kidney proximal tubular cell; KD, knockdown; NC, negative control.

HSF1 knockdown promotes RPTC invasion. As HSF1 negatively affected the RPTC cell migration, and that this inhibitory effect was demonstrated to occur via regulation of the TGF- $\beta 1$ signaling pathway, the invasive ability of HSF1 $\mathrm{KD}$ and NC cells was then evaluated. Following knockdown of HSF1 in RPTCs, the number of cells penetrating the Matrigel was markedly increased (Fig. 4A). Upon treating with $10 \mathrm{mM}$ TGF- $\beta 1$ inhibitor SB431542, the RPTC invasive ability of the HSF1 KD and scramble groups was decreased by 70.7 and $52 \%$, respectively (Fig. 4B). In addition, no significant difference was observed in the invasive abilities between the HSF1 shRNA1 and shRNA2 groups (data not shown).

HSF1 does not affect RPTC proliferation. The changes in cell migration may be due to differing proliferative abilities during the wound healing process. Therefore, the present study compared the numbers of living cells in the HSF1 KD and scramble cell lines following culture for $0,12,24$ and $48 \mathrm{~h}$. The results indicated that their growth curves were similar (Fig. 4C). In addition, the expression of proliferation marker protein Ki-67 was assessed. As demonstrated in Fig. S1, there was no marked difference between HSF1 knockdown and control cells, whether in 0 or $24 \mathrm{~h}$ after culture. Following treatment with the TGF- $\beta 1$ inhibitor SB431542 for $24 \mathrm{~h}$, no significant difference in the cell number in the 2 cell lines was observed (Fig. 4D), indicating that the effect of HSF1 or TGF- $\beta 1$ signaling on cell migration was not mediated through an inhibition of proliferation.

\section{Discussion}

In the present study, the effects of HSF1 on kidney tubular cell migration and invasion were investigated. HSF1 was demonstrated to be protective in kidney epithelial cells during cisplatin-induced AKI in our previous study (3). In addition, the migration of vascular endothelial (23) or macrophage (24) cells contributes to the repair of cisplatin-induced AKI. Therefore, we hypothesized that HSF1 may serve a protective role against injury by promoting cell migration. Unexpectedly, HSF1 knockdown promoted kidney tubular cell migration and invasion. In addition, the regulatory effects of HSF1 on cell migration were associated with the induced expression of the TGF- $\beta 1 /$ phosphorylated (p)-Smad $2 / 3$ pathway proteins. These data suggest that, in addition to serving a protective role against AKI, HSF1 also has the effect of inhibiting kidney tubular cell migration.

The effect of HSF1 on the migration process appears to vary in different cell lines. For example, HSF1 was demonstrated to 
be able to stimulate osteosarcoma cell migration and upregulate EGF receptor 1 expression (6). HSF1 activation was also suggested to be associated with poor outcomes in patients with breast and lung cancer (25). In a separate study, it was revealed that HSF1 promoted the inhibition of EMT-associated migration in hepatocellular carcinoma cells and the upregulation of epithelial cadherin (E-cadherin) expression (8). These data suggest that HSF1 may affect cell migration by regulating different signaling molecules in different disease models.

It has been established that cell motility is closely associated with the activation of the TGF- $\beta 1$ signaling pathway $(16,17)$. As cell motility was enhanced in the HSF1 KD cell line, we hypothesized that certain TGF- $\beta 1$ pathway proteins may be highly expressed in RPTC HSF1 KD cells. The results of the present study demonstrated that Smad2/3 phosphorylation was induced in HSF1 KD cells. Therefore, TGF- $\beta 1 / \mathrm{Smad} 2 / 3$ signaling contributes at least partially to promoting cell migration. Of note, TGF- $\beta 1$ expression was significantly upregulated at the edge of the wound, which is important for cell migration. Notably, it was previously demonstrated that treatment of human kidney 2 cells with TGF- $\beta 1$ protein may lead to a marked inhibition of migration (26); Supplementation with exogenous TGF- $\beta 1$ also significantly inhibited proliferation and migration of oral mucosal fibroblasts (27); an additional in vivo study indicated that overexpressing TGF- $\beta 1$ exacerbated renal injury while latent TGF- $\beta 1$ inhibited renal inflammation and fibrosis (28). Therefore, it is possible that latent TGF- $\beta 1$ promotes cell migration, while excess TGF- $\beta 1$ has the opposite effect. In addition, HSF1 knockdown may induce endogenous TGF- $\beta 1$ signaling pathway activation.

HSF1 knockdown causes the promotion of kidney tubular cell migration by regulating the TGF- $\beta 1$ signaling pathway. Our first hypothesis was that the promotive effect may also occur through regulating E-cadherin expression, as cell migration usually is associated with EMT. In addition, it has been demonstrated previously that HSF1 promoted the inhibition of EMT-associated migration in hepatocellular carcinoma cells by downregulating E-cadherin expression (8). However, there was no induction of E-cadherin or vimentin expression in the present study, thereby suggesting that the enhanced cell migration caused by HSF1 knockdown is not associated with cell adhesion proteins. E-cadherin is primarily expressed in renal distal tubular cells, whereas RPTCs contain mainly neural cadherin (29), therefore, E-cadherin may not be involved in the process of HSF1-mediated regulation of RPTC migration.

A potential mechanism by which HSF1 knockdown leads to the activation of the TGF- $\beta 1$ signaling pathway is that HSF1 decreases TGF- $\beta 1$ activation by regulating heat shock protein (HSP) expression. For example, HSP70 and HSP90 regulate TGF- $\beta$ signaling through opposing mechanisms (30). TGF- $\beta 1$-induced cell motility was also suggested to be associated with HSP27 activation in prostate epithelial cells (31). An additional explanation why HSF1 is able to regulate TGF- $\beta 1$ activation may be due to proteins not associated with the heat shock response. For example, HSF1 was suggested to be able to inhibit the activation of a variety of transcription factors, including $\mathrm{NF}-\kappa \mathrm{B}$ (32). It is possible, therefore, that the enhancement of cell migration in RPTC HSF1 KD cells may be caused by changes in expression of certain HSPs or the $\mathrm{NF}-\kappa \mathrm{B}$ signaling pathway.
In conclusion, the present study demonstrated that HSF1 suppressed RPTC migration by regulating the TGF- $\beta 1 /$ $\mathrm{p}-\mathrm{Smad} 2 / 3$ signaling pathway. The results of the present study suggested that HSF1 may serve an inhibitory role during renal fibrosis and provide a novel strategy for the treatment of kidney injury.

\section{Acknowledgements}

The authors would like to thank professor Zheng Dong (Augusta University) for his academic advice and technical support.

\section{Funding}

The present study was funded by the National Natural Science Foundation of China (grant no. 81970592 and U1404826), Key Scientific and Technological Project of Henan Province (grant no. 192102310314), Research Fund of Henan University and Shanghai Pujiang Program (grant no. 17PJ1411100).

\section{Availability of data and materials}

The datasets used and/or analyzed during the current study are available from the corresponding author on reasonable request.

\section{Authors' contributions}

QL conceived and designed the current study. YLi performed the experiments. YLi, QL, BH, YLiu, YZ, JH and YM analyzed the data. YLi drafted the manuscript, and YLi, QL, $\mathrm{BH}, \mathrm{YLiu}, \mathrm{YZ}, \mathrm{JH}$ and YM edited and revised the manuscript. All authors approved the final version of the manuscript.

\section{Ethics approval and consent to participate}

Not applicable.

\section{Patient consent for publication}

Not applicable.

\section{Competing interests}

The authors declare that they have no competing interests.

\section{References}

1. Duffield JS, Park KM, Hsiao LL, Kelley VR, Scadden DT, Ichimura $\mathrm{T}$ and Bonventre $\mathrm{J}$ : Restoration of tubular epithelial cells during repair of the postischemic kidney occurs independently of bone marrow-derived stem cells. J Clin Invest 115: 1743-1755, 2005.

2. Müller S, Djudjaj S, Lange J, Iacovescu M, Goppelt-Struebe M and Boor P: HIF stabilization inhibits renal epithelial cell migration and is associated with cytoskeletal alterations. Sci Rep 8: 9497, 2018.

3. Lou Q, Hu Y, Ma Y and Dong Z: Heat shock factor 1 induces crystallin- $\alpha B$ to protect against cisplatin nephrotoxicity. Am J Physiol Renal Physiol 311: F94-F102, 2016.

4. Sreedharan R, Chen S, Miller M, Haribhai D, Williams CB and Van Why SK: Mice with an absent stress response are protected against ischemic renal injury. Kidney Int 86: 515-524, 2014. 
5. Chen K, Qian W, Li J, Jiang Z, Cheng L, Yan B, Cao J, Sun L, Zhou C, Lei M, et al: Loss of AMPK activation promotes the invasion and metastasis of pancreatic cancer through an HSF1-dependent pathway. Mol Oncol 11: 1475-1492, 2017.

6. Zhou Z, Li Y, Jia Q, Wang Z, Wang X, Hu J and Xiao J: Heat shock transcription factor 1 promotes the proliferation, migration and invasion of osteosarcoma cells. Cell Prolif 50, 2017.

7. Li Y, Xu D, Bao C, Zhang Y, Chen D, Zhao F, Ding J, Liang L, Wang Q, Liu L, et al: MicroRNA-135b, a HSF1 target, promotes tumor invasion and metastasis by regulating RECK and EVI5 in hepatocellular carcinoma. Oncotarget 6: 2421-2433, 2015.

8. Liu D, Sun L, Qin X, Liu T, Zhang S, Liu Y, Li S and Guo K: HSF1 promotes the inhibition of EMT-associated migration by low glucose via directly regulating Snaill expression in HCC cells. Discov Med 22: 87-96, 2016.

9. Toma-Jonik A, Widlak W, Korfanty J, Cichon T, Smolarczyk R, Gogler-Piglowska A, Widlak P and Vydra N: Active heat shock transcription factor 1 supports migration of the melanoma cells via vinculin down-regulation. Cell Signal 27: 394-401, 2015

10. Scheraga RG, Thompson C, Tulapurkar ME, Nagarsekar AC, Cowan M, Potla R, Sun J, Cai R, Logun C, Shelhamer J, et al: Activation of heat shock response augments fibroblast growth factor-1 expression in wounded lung epithelium. Am J Physiol Lung Cell Mol Physiol 311: L941-L955, 2016.

11. Wang JK, Wang WJ, Cai HY, Du BB, Mai P, Zhang LJ, Ma W, $\mathrm{Hu}$ YG, Feng SF and Miao GY: MFAP2 promotes epithelial-mesenchymal transition in gastric cancer cells by activating TGF- $\beta /$ SMAD2/3 signaling pathway. Onco Targets Ther 11: 4001-4017, 2018

12. Deng G, Chen L, Zhang Y, Fan S, Li W, Lu J and Chen X: Fucosyltransferase 2 induced epithelial-mesenchymal transition via TGF- $\beta /$ Smad signaling pathway in lung adenocarcinaoma. Exp Cell Res 370: 613-622, 2018.

13. Huang G, Du MY, Zhu H, Zhang N, Lu ZW, Qian LX, Zhang W, Tian X, He X and Yin L: MiRNA-34a reversed TGF- $\beta$-induced epithelial-mesenchymal transition via suppression of SMAD4 in NPC cells. Biomed Pharmacother 106: 217-224, 2018.

14. Liu Y, Wang JX, Huang D, Wang B, Li LL, Li XX, Ni P, Dong XL, Xia W, Yu CX, et al: PMLIV overexpression promotes TGF- $\beta$-associated epithelial-mesenchymal transition and migration in MCF-7 cancer cells. J Cell Physiol 233: 9575-9583, 2018.

15. Yang R, Liang J, Xu GX, Ding LM, Huang HM, Su QZ, Yan J and Li YC: Human cytomegalovirus glycoprotein B inhibits migration of breast cancer MDA-MB-231 cells and impairs TGF- $3 /$ Smad2/3 expression. Oncol Lett 15: 7730-7738, 2018

16. Chen CA, Chang JM, Chang EE, Chen HC and Yang YL: TGF- $\beta 1$ modulates podocyte migration by regulating the expression of integrin- $\beta 1$ and $-\beta 3$ through different signaling pathways. Biomed Pharmacother 105: 974-980, 2018.

17. Yang J, Zhang N, Gao R, Zhu Y, Zhang Z, Xu X, Wang J, Li Z, Liu X, Li Z, et al: TGF- $\beta 1$ induced fascin1 expression facilitates the migration and invasion of kidney carcinoma cells through ERK and JNK signaling pathways. Biochem Biophys Res Commun 501: 913-919, 2018

18. Wang DG, Li TM and Liu X: RHCG suppresses cervical cancer progression through inhibiting migration and inducing apoptosis regulated by TGF- $\beta 1$. Biochem Biophys Res Commun 503 $86-93,2018$.
19. Kays SE, Nowak G and Schnellmann RG: Transforming growth factor-beta 1 inhibits regeneration of renal proximal tubular cells after oxidant exposure. J Biochem Toxicol 11: 79-84, 1996.

20. Hallman MA, Zhuang S and Schnellmann RG: Regulation of dedifferentiation and redifferentiation in renal proximal tubular cells by the epidermal growth factor receptor. J Pharmacol Exp Ther 325: 520-528, 2008.

21. Long M, Cai L, Li W, Zhang L, Guo S, Zhang R, Zheng Y, Liu X, Wang M, Zhou X, et al: DPP-4 inhibitors improve diabetic wound healing via direct and indirect promotion of epithelial-mesenchymal transition and reduction of scarring. Diabetes 67: 518-531, 2018.

22. Zhou X, Zhang W, Yao Q, Zhang H, Dong G, Zhang M, Liu Y, Chen JK and Dong Z: Exosome production and its regulation of EGFR during wound healing in renal tubular cells. Am J Physiol Renal Physiol 312: F963-F970, 2017.

23. Zhang R, Yin L, Zhang B, Shi H, Sun Y, Ji C, Chen J, Wu P, Zhang L, Xu W and Qian $\mathrm{H}$ : Resveratrol improves human umbilical cord-derived mesenchymal stem cells repair for cisplatin-induced acute kidney injury. Cell Death Dis 9: 965, 2018.

24. Li J, Tang Y, Tang PMK, Huang XR, Carlsson-Skwirut C, Da Costa L, Aspesi A, Fröhlich S, Szczęśniak P, et al: Blocking macrophage migration inhibitory factor protects against cisplatin-induced acute kidney injury in mice. Mol Ther 26: 2523-2532, 2018

25. Scherz-Shouval R, Santagata S, Mendillo ML, Sholl LM, Ben-Aharon I, Beck AH, Dias-Santagata D, Koeva M, Stemmer SM, Whitesell L and Lindquist S: The reprogramming of tumor stroma by HSF1 is a potent enabler of malignancy. Cell 158: 564-578, 2014.

26. Tian YC and Phillips AO: TGF-beta1-mediated inhibition of HK-2 cell migration. J Am Soc Nephrol 14: 631-640, 2003.

27. Dally J, Khan JS, Voisey A, Charalambous C, John HL, Woods EL Steadman R, Moseley R and Midgley AC: Hepatocyte growth factor mediates enhanced wound healing responses and resistance to transforming growth factor- $\beta_{1}$-driven myofibroblast differentiation in oral mucosal fibroblasts. Int J Mol Sci 18: E1843, 2017.

28. Lan HY: Diverse roles of TGF- $\beta /$ Smads in renal fibrosis and inflammation. Int J Biol Sci 7: 1056-1067, 2011.

29. Kroening S, Neubauer E, Wullich B, Aten J and GoppeltStruebe M: Characterization of connective tissue growth factor expression in primary cultures of human tubular epithelial cells: Modulation by hypoxia. Am J Physiol Renal Physiol 298: F796-F806, 2010.

30. Shang Y, Xu X, Duan X, Guo J, Wang Y, Ren F, He D and Chang Z: Hsp70 and Hsp90 oppositely regulate TGF- $\beta$ signaling through CHIP/Stub1. Biochem Biophys Res Commun 446: 387-392, 2014.

31. Di K, Wong YC and Wang X: Id-1 promotes TGF-beta1-induced cell motility through HSP27 activation and disassembly of adherens junction in prostate epithelial cells. Exp Cell Res 313: 3983-3999, 2007.

32. Wirth D, Bureau F, Melotte D, Christians E and Gustin P: Evidence for a role of heat shock factor 1 in inhibition of NF-kappaB pathway during heat shock response-mediated lung protection. Am J Physiol Lung Cell Mol Physiol 287: L953-L961, 2004. 